\title{
Recovery of Silicon Carbide monitor irradiation temperature via continuous resistance measurement during annealing Part II
}

Mitchell A Plummer, Ahmad Y Al Rashdan, Ashley A Lambson, Malwina A Wilding, Troy Unruh

September 2019

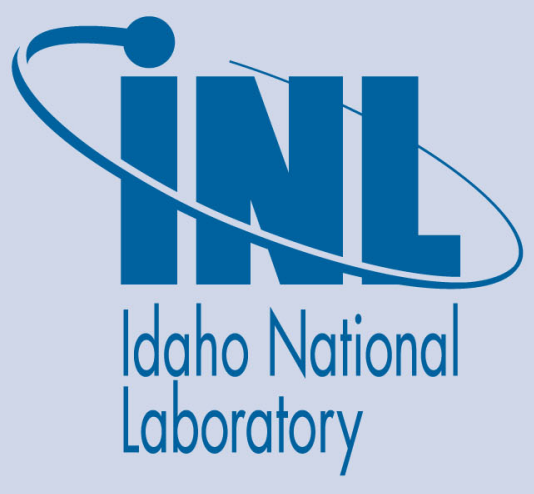

The INL is a U.S. Department of Energy National Laboratory operated by Battelle Energy Alliance 


\title{
Recovery of Silicon Carbide monitor irradiation temperature via continuous resistance measurement during annealing Part II
}

\author{
Mitchell A Plummer, Ahmad Y Al Rashdan, Ashley A Lambson, Malwina A \\ Wilding, Troy Unruh
}

September 2019

Idaho National Laboratory Idaho Falls, Idaho 83415

http://www.inl.gov

Prepared for the

U.S. Department of Energy

Under DOE Idaho Operations Office

Contract DE-AC07-05ID14517 


\title{
Recovery of Silicon Carbide monitor irradiation temperature via continuous resistance measurement during annealing - Part II
}

\author{
Mitchell Plummer, Ahmad Al Rashdan, Ashley Lambson, Malwina Wilding, Troy Unruh
}

\section{Abstract}

Silicon carbide $(\mathrm{SiC})$ monitors provide a means of measuring peak irradiation temperature of experiment capsules in nuclear irradiation experiments. Neutron irradiation of a $\mathrm{SiC}$ monitor causes permanent lattice changes that are removed by annealing via heating to a temperature that exceeds the peak irradiation temperature. The annealing process results in changes to $\mathrm{SiC}$ physical characteristics that can be observed during the annealing process. This paper presents results of a method aimed at using electrical resistance, measured during a two-pass heating - cooling cycle as a means of recovering the irradiation temperature of a SiC monitor. Results indicate that the relationship between resistance and temperature of a $\mathrm{SiC}$ monitor shows a significant change in slope when the peak irradiation temperature is reached. This demonstrates the potential for this method to replace the current manual, and lengthy, process of post irradiation examination used to extract the peak irradiation temperature from irradiated $\mathrm{SiC}$ monitors.

\section{Key Words}

Silicon Carbide, temperature sensors, nuclear measurements, electrical resistance

\section{Introduction}

Silicon carbide $(\mathrm{SiC})$ monitors are routinely used for measurement of peak irradiation temperature in nuclear irradiation experiments in research reactors like the Nuclear Science User Facilities - Advanced Test Reactor (ATR) at Idaho National Laboratory (INL) (Rempe et al., 2010; Daw et al., 2013). Irradiation of the monitors at a specific temperature results in lattice structural changes that can be removed by annealing (Littler, 1962; Huang and Ghoniem, 1997). Identification of the temperature at which the annealing rate is greatest thus provides a measure of the irradiation temperature of the monitor. Because $\mathrm{SiC}$ monitors measure over a continuous range of peak irradiation temperature, they have advantages over the discretized measurement associated with using melt wires, which are the most common type of sensors used in research reactors to capture peak irradiation temperature. However, recovery of the irradiation temperature from $\mathrm{SiC}$ monitors during Post-Irradiation Examination (PIE) is currently accomplished with a time-consuming isochronal annealing process. That method involves measurement of electrical resistivity during a cyclic heating and cooling process (Rempe et al., 2010). In each cycle, the monitor is heated to an increasingly higher temperature in the annealing furnace, and then returned to a controlled low temperature. At the end of each cycle, the monitor is removed from the furnace and its resistance is measured to determine if that property has been altered by the heating process, a change indicative of the structural changes associated with annealing. The method requires many heating cycles to analyze one monitor. As a result, INL is evaluating replacement of that cyclic isochronal heating approach with an automated approach requiring only one or two heating cycles that could speed up the PIE process and possibly improve measurement accuracy. In this approach, each heating cycle extends above the likely annealing temperature, and electrical resistance of the monitor is measured throughout the heating/cooling process. Similar efforts, using continuous dilatometry, have 
been tested at Oakridge National Laboratory (Campbell et al., 2016; Field et al., 2019). This effort focuses on continuous resistance measurements, as a potentially less expensive method of irradiation temperature recovery.

The initial phase of this effort targeted designing the system to enable online measurement of the SiC monitor's electrical resistance and identify the noise contributors that interfere with the process (AI Rashdan et al., 2017). These noise factors include corrosion of peripherals, thermal transient lag between the monitor and furnace, and thermal expansion effects, and are not the focus of this paper. This paper targets the results of the efforts using the system after many of the noise contributors have been addressed by optimizing system parameters.

\section{Methods}

Resistance of the SiC monitor is measured continuously during heating and cooling, with the apparatus described in Rashdan et al., 2017. To minimize thermal perturbations, which increase uncertainty in the temperature measurement, a constant heating rate is applied during the measurements. As a result, the rate of temperature increase decreases with time (Figure 1). To bring the temperature to the range of interest more quickly, a higher heating rate is applied until the oven reaches approximately $150^{\circ} \mathrm{C}$, at which point temperature is allowed to stabilize before the final, lower, heating rate is applied. When the temperature reaches $475^{\circ} \mathrm{C}$, the heating element is shut off, and the oven temperature cools at a slightly slower rate than during heating. Each heating/cooling cycle provides two segments of data describing the relationship between temperature and resistance.

In this study, we measured resistance and temperature through three heating/cooling cycles for each sample. These measurements were made on eight samples, four of which had been previously used in an isochronal annealing measurement process. The four previously used samples were not expected to provide a good test of the proposed new method of irradiation temperature detection, but were included to examine repeatability of resistance-temperature measurement. Analyses in this discussion focus on samples M1-High-B, M2-Med-B, M2-Low-

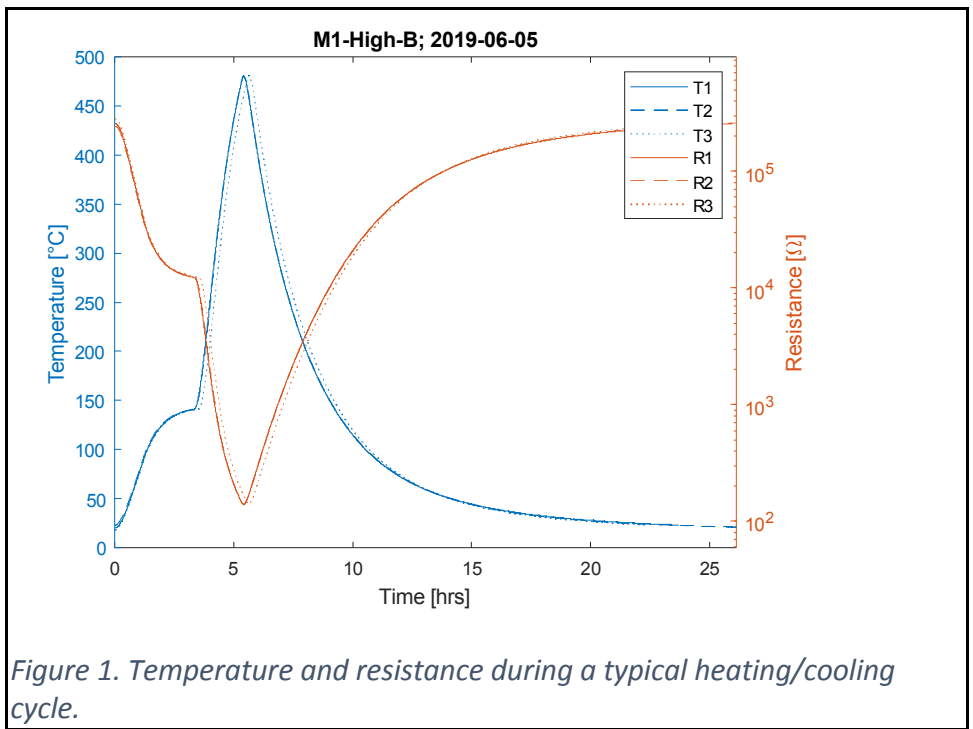
cycle.

$B$, and M2-Med-B, which were first reheated (following their irradiation) in this study. Plots illustrating the analysis process utilize data from sample M1-High-B.

Through interpolation of the time-temperature and time-resistance data, we put the resistance data for each sample on a common temperature scale, to allow comparison of the resistance vs temperature curve between segments (Figure 2A). The goal of the analysis is to use changes in the shape of the resistance-temperature curves to identify the $\mathrm{SiC}$ irradiation temperature. As a reference for departure of resistance from the annealed condition, we calculate the average resistance of all segments at each temperature. Because the $\mathrm{SiC}$ monitor spends $\sim 5.5$ hours above a temperature of $150^{\circ} \mathrm{C}$ in each cycle, 
this mean resistance curve should be heavily weighted toward the annealed state.

\section{Results}

The departure from that mean resistance, ie. $R(T)-R_{\text {mean }}(T)$, is plotted to identify changes in the resistance - temperature curve that might indicate the irradiation temperature (Figure $2 \mathrm{~B}$ ). The departure curves generally exhibit several pronounced characteristics. First the heating and cooling segments differ in the direction of their departure, with the resistance during heating generally higher than the resistance during cooling. This could reflect systematic measurement error associated with the measurement of a transient state, or hysteresis in the resistance dependence on temperature. Second, the changes in the heating rate that occur just below $150^{\circ} \mathrm{C}$ cause a significant perturbation that is unrelated to the annealing process, so that region is excluded from the analysis. Finally, the resistancetemperature curve of the first heating cycle is significantly different than subsequent heating curves, while the first cooling segment curve is similar to subsequent cooling curves (Figure 2B). This is consistent with the expectation that annealing is largely accomplished during the first heating segment. To better examine differences in the shapes of the departure curves, we plot the negative of the cooling departure curves with the heating departure curves, and focus on changes above $175^{\circ} \mathrm{C}$ (Figure $2 \mathrm{C}$ ), after which the transient induced by changes in heating rate has disappeared.
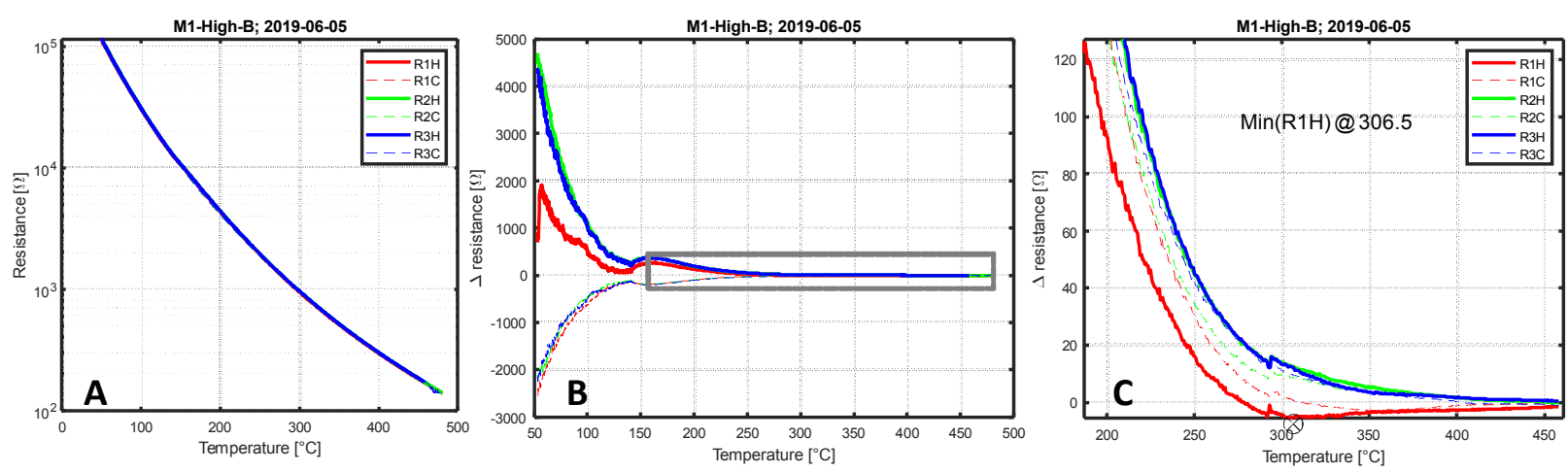

Figure 2. (A) Resistance vs temperature for each of the 3 heating and 3 cooling segments produced in the 3 heating/cooling cycles and (B) the difference in resistance from the mean of 6 segments as a function of temperature $\left(R(T)-R_{\text {mean }}(T)\right)$. Dashed region in $B$ shows the data subset used in $C$, where the cooling segment departure curves are expressed as $R_{\text {mean }}(T)-R(T)$.

Annealing that occurs during heating or cooling is expected to alter the sign of the first derivative (with respect to temperature) of the departure curve. That is, the resistance of the irradiated sample is initially lower than the fully annealed sample, and if no annealing occurs during a segment, the difference from the mean should simply decrease with the resistance. When annealing begins to alter the sample, however, resistance should increase, reducing the difference from the annealed condition and thus the resistance departure from the mean. This behavior would be expected to be most pronounced in the first heating curve, where the annealing effect should be greatest. In the example displayed here, the first heating curve exhibits a change in direction at a temperature $\left(307^{\circ} \mathrm{C}\right)$ that corresponds closely to the provided irradiation temperature $\left(310^{\circ} \mathrm{C}\right)$. The cooling curve also exhibits a change in direction, but at a higher temperature $\left(350^{\circ} \mathrm{C}\right)$, consistent with the hypothesis that incomplete annealing during the heating cycle had a greater effect near the annealing temperature than above it. For the other samples first annealed in this study, the temperatures indicated from the zero-slope calculations are $460^{\circ} \mathrm{C}$, for $\mathrm{M} 1-\mathrm{Med}-\mathrm{B}$, and $338^{\circ} \mathrm{C}$, for M2-Med-B. An irradiation temperature for M2Low-B could not be determined in the same manner as the other samples. These temperatures differ by 
$50 \mathrm{~K}$ and $-42 \mathrm{~K}$ from the expected irradiation temperatures.

Based on theory and the example described here, the location of the change of sign of the derivative of the first heating cycle departure curve, with respect to temperature, may be a relatively accurate measure of the irradiation temperature of a $\mathrm{SiC}$ monitor. The other samples used in this study, which had previously undergone an isochronal annealing process, were not expected to be a good test of this method because that process involved - for each sample - at least two hours above $200^{\circ} \mathrm{C}$ (Figure 3 ), which is similar to the time spent above that temperature in a single segment of the heating/cooling cycles used in this study. Application of the proposed method to those samples, however, illustrates much better comparison than expected. Three of the five samples yield a calculated irradiation temperature that is within $8^{\circ} \mathrm{C}$ of the provided temperature, while the other two yield temperatures that are $\sim 50^{\circ} \mathrm{C}$ different from the provided temperature (Table 1, Figure 4). The probability of successful application is generally evident in plots comparing the resistance during heating curves as given in Figure 2B. Samples for which the calculated irradiation temperature closely matches the provided temperature, the resistance of the initial heating curve is substantially different from the subsequent heating curves. Of the other two samples, the departure curve was either very similar to the subsequent heating curves, or close to zero.

Table 1. Sample details

$\begin{array}{lcccccc}\text { Sample ID } & \begin{array}{c}\text { Given } \\ \text { irradiation } \\ \text { temperature }\end{array} & \begin{array}{c}\text { Starting } \\ \text { date }\end{array} & \begin{array}{c}\text { Calculated T } \\ {\left[{ }^{\circ} \mathrm{C}\right] \text {, using }} \\ \text { mean of } \\ \text { segments 2-4 }\end{array} & \begin{array}{c}\text { Calculated T } \\ {\left[{ }^{\circ} \mathrm{C}\right] \text {, using }} \\ \text { mean of all 6 } \\ \text { segments }\end{array} & \begin{array}{c}\text { Max } \\ \text { isochronal } \\ \text { T }\left[{ }^{\circ} \mathrm{C}\right]\end{array} \\ \text { M2-High-B } & - & 3 / 19 / 2019 & 315 & & 495 \\ \text { M1-Med-B } & - & 410 & 4 / 8 / 2019 & 460 & 460 & 375 \\ \text { M1-Med-A } & 0.5 & 390 & 5 / 1 / 2019 & 342 & 325 & 385 \\ \text { M1-High-A } & 0.5 & 320 & 5 / 14 / 2019 & 313 & 313 & 440 \\ \text { M2-High-A } & 1.4 & 330 & 5 / 20 / 2019 & 324 & 324 & - \\ \text { M2-Med-A } & 1.4 & 380 & 5 / 28 / 2019 & 379 & 379 & 307 \\ \text { M1-High-B } & & 310 & 6 / 5 / 2019 & 307 & - & -\end{array}$

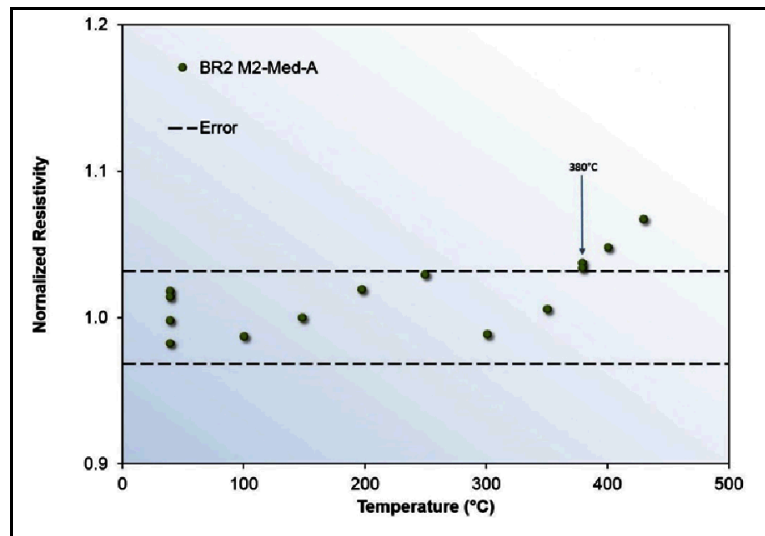

Figure 3. Room temperature resistance normalized to initial room temperature resistance, after isochronal annealing at specified temperatures. Each isochronal annealing step involved rapid heating to the specified temperature. n aintainoing that value for 30 minutes and then cooling the sample to $40^{\circ} \mathrm{C}$ for resistance measurement.

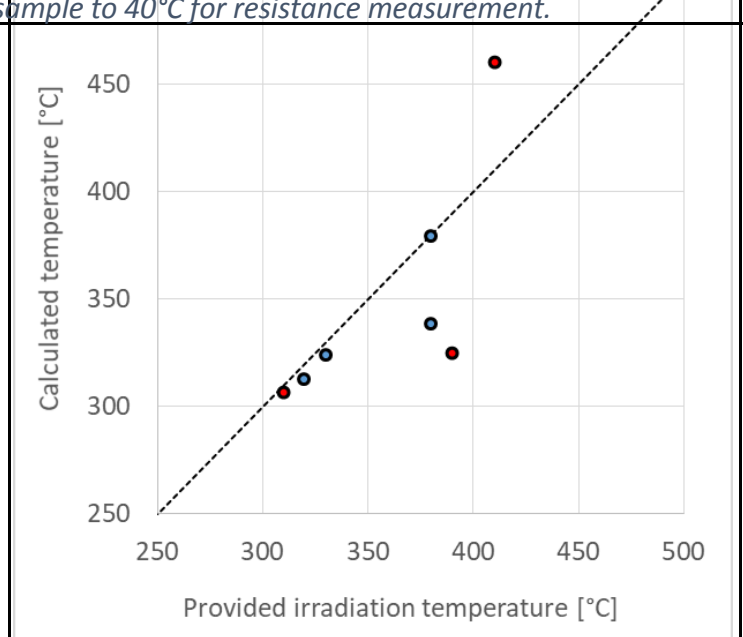

Figure 4. Comparison of irradiation temperature calculated using the method proposed in this study (ordinate axis), with the irradiation temperature provided with the samples (abscissa). Red symbols indicate SiC monitors first reheated in this study. 
In this study three heating/cooling cycles were applied to each sample to examine changes in the resistance-temperature curves induced by heating. In practice, this may require only two such cycles, and excluding the first heating segment from the mean may also improve the method. Calculations using that approach yielded nearly identical results to those using a mean of the six segments of three cycles (Table 1).

Finally, we note that other methods of detecting the effect of annealing on the resistance vs temperature curve may provide similar results. For example, using the ratio of resistances (Figure 5) between the first and second heating segments (Cycle 1 vs Cycle 2), we obtain an irradiation temperature of $321^{\circ} \mathrm{C}$, while the ratio of the first and third heating cycles yields an irradiation temperature of $307^{\circ} \mathrm{C}$. While both of those values are close to the provided temperature of $310^{\circ} \mathrm{C}$, that method does not yield good estimates for the samples that had previously undergone isochronal annealing, suggesting overall poorer sensitivity to the difference method incorporating the mean of heating and cooling cycles.

\section{Conclusion}

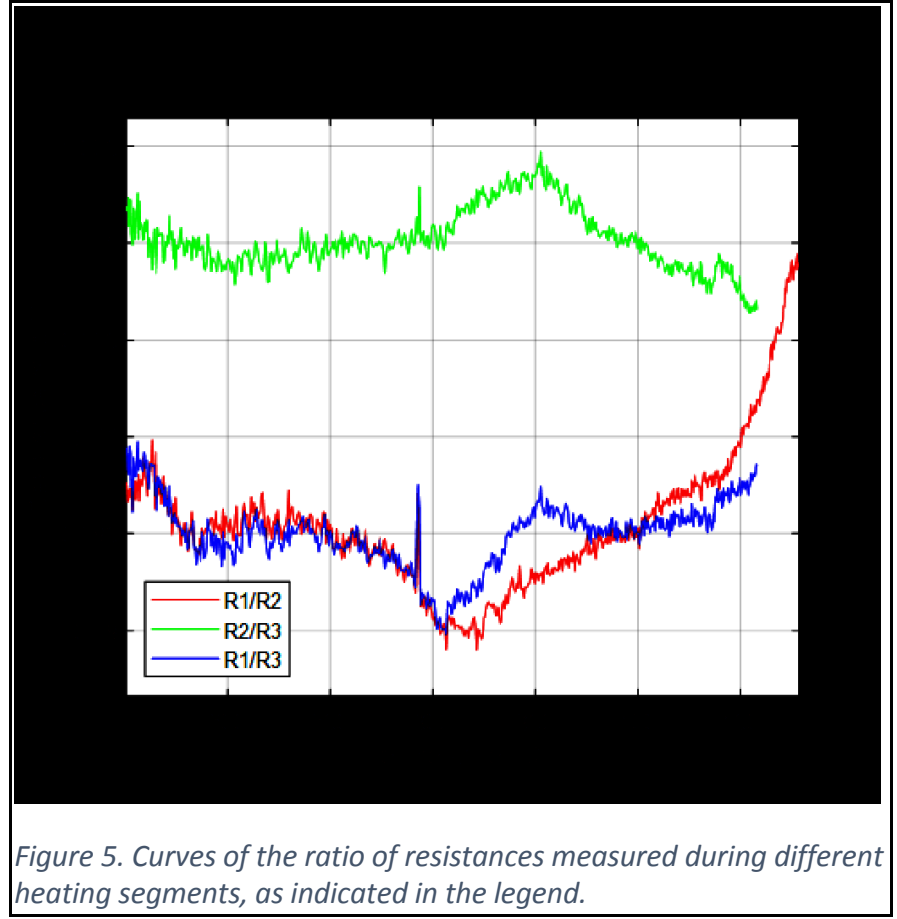

A means of using continuous measurement of resistance of $\mathrm{SiC}$ monitors during heating/cooling has been developed, that is easily automated, and involves relatively inexpensive resistance measuring equipment. The method applies a constant-power heating rate during the annealing process, in order to minimize controller-derived perturbations in the heating rate. The analysis process essentially compares the resistance during the first heating period to the average of the resistance measured in subsequent heating and cooling periods. The departure from the mean typically decreases with temperature until the irradiation temperature is reached, at which point the resistance departure decreases. We estimate the irradiation temperature as the zero-slope inflection point of that curve. Of eight samples analyzed thus far, the average error in the recovered irradiation temperature is $11 \mathrm{~K}$, with a maximum error of $65 \mathrm{~K}$. Four of the samples analyzed had undergone several heating cooling cycles as part of isochronal annealing resistance measurements (Davis et al., 2018). The accuracy of the recovered irradiation temperature for those samples was as good as the previously unannealed samples that were the focus of this study. While further testing is needed to refine the method, this appears to be viable means of recovering irradiation temperature of silicon monitors during post-irradiation examination.

\section{References}


Rempe, J., D.L. Knudson, K.G. Condie, , J.E. Daw, , H. Ban, , B.S. Fox, and G.E. Kohse, 2010, New sensors for the advanced test reactor national scientific user facility, IEEE Transactions on Nuclear Science, vol. 57 no. 5 2653-2661.

Daw, J., J. Rempe, D. Knudson, T. Unruh, B. Chase, K. Davis, and A. Palmer, 2013, Temperature monitoring options available at the Idaho national laboratory advanced test reactor, in AIP Conference Proceedings, vol. 1552, no. 1, 970-975.

Littler, D., 1962, Properties of Reactor Materials and the Effects of Radiation Damage, Proceedings of the International Conference held at Berkeley Castle, Butterworths.

Huang, H. and N. Ghoniem, 1997, A swelling model for stoichiometric SiC at temperatures below $1000 \mathrm{C}$ under neutron irradiation, Journal of nuclear materials, vol. 250, no. 2, 192-199.

Rempe, J., K. Condie, D. Knudson, and L. Snead, 2010, Comparison measurements of silicon carbide temperature monitors, IEEE Transactions on Nuclear Science, vol. 57 no. 3, 1589-1594.

Al Rashdan, A., K. Davis, T. Unruh, and J. Daw, 2017, Silicon Carbide Temperature Monitor Online Evaluation, PLN-5465.

Davis, K., T.C. Unruh, P. Calderoni, S. Van Dyck, A. Gusarov, K. Verner, A. Al Rashdan, A. Lambson, 2018, Evaluations of BR2 Silicon Carbide Temperature Monitors, INL/EXT-18-46086.

Campbell, A., W. Porter, Y. Katoh, and L. Snead, 2016, Method for analyzing passive silicon carbide thermometry with a continuous dilatometer to determine irradiation temperature, Nuclear Instruments and Methods in Physics Research Section B: Beam Interactions with Materials and Atoms, Vol. 370, 49-58.

Field, K., J. McDuffee, J. Geringer, C. Petrie, Y. Katoh, 2019, Evaluation of the continuous dilatometer method of silicon carbide thermometry for passive irradiation temperature determination, Nuclear Instruments and Methods in Physics Research B: Beam Interactions with Materials and Atoms, Vol. 445, 4656.

\section{Acknowledgements}

INL is a multi-program laboratory operated by Battelle Energy Alliance LLC, for the United States Department of Energy under Contract DE-AC07-05ID14517. This work of authorship was prepared as an account of work sponsored by an agency of the United States Government. Neither the United States Government, nor any agency thereof, nor any of their employees makes any warranty, express or implied, or assumes any legal liability or responsibility for the accuracy, completeness, or usefulness of any information, apparatus, product, or process disclosed, or represents that its use would not infringe privately-owned rights. The United States Government retains, and the publisher, by accepting the article for publication, acknowledges that the United States Government retains a nonexclusive, paidup, irrevocable, world-wide license to publish or reproduce the published form of this manuscript, or allow others to do so, for United States Government purposes. The views and opinions of authors expressed herein do not necessarily state or reflect those of the United States government or any agency thereof. 


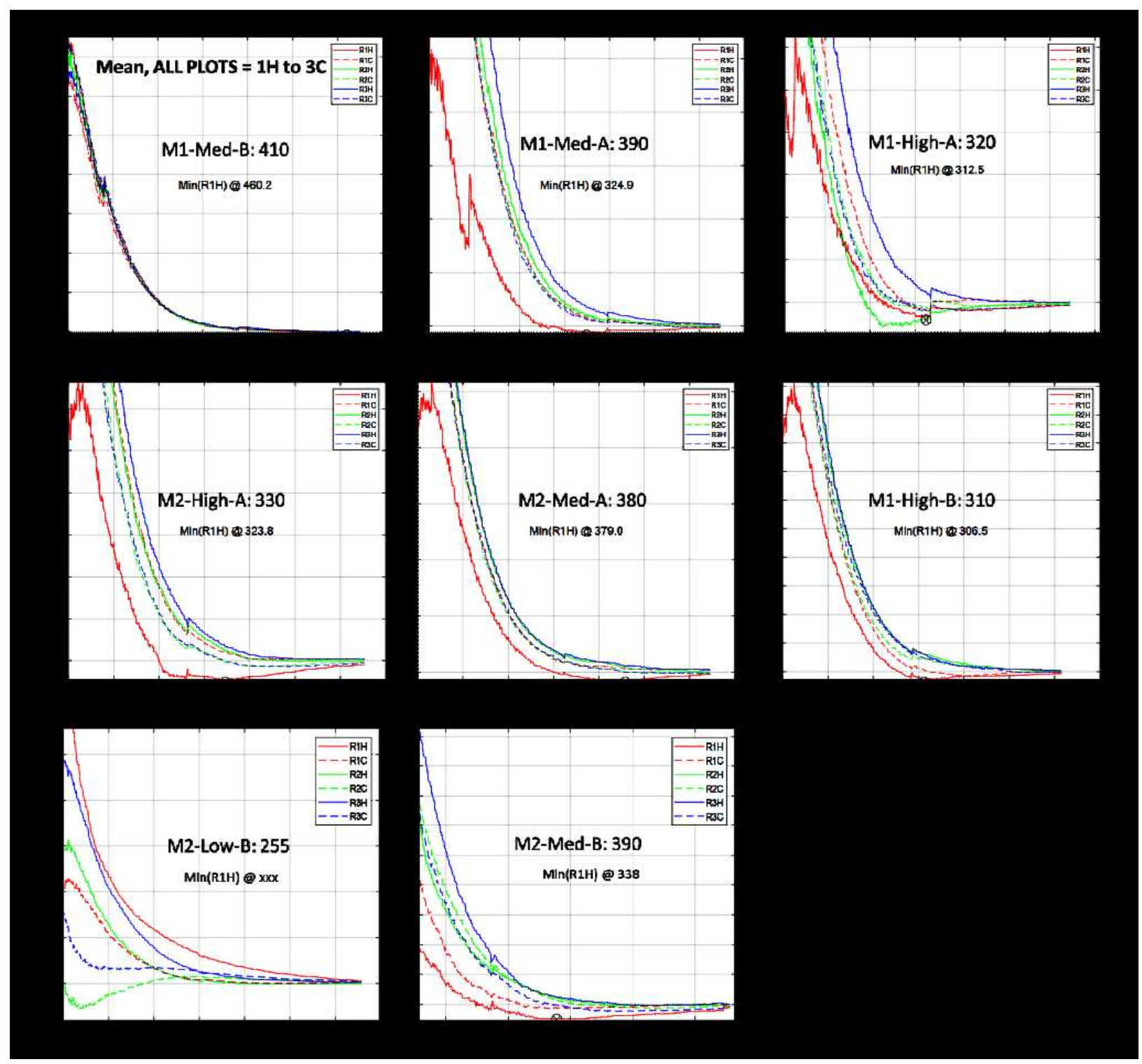

